\title{
Selective Posterior Epiphysiodesis of the Triradiate Cartilage of the Acetabulum: Preliminary Results of an Experimental Study in Rabbits
}

\author{
Bibiana Dello Russo \\ Orthopaedic Surgeon, Hospital Nacional de Pediatría J.P. Garrahan, Buenos Aires, Argentina \\ Email: bibianadellorusso@yahoo.com.ar
}

Received 22 May 2016; accepted 1 August 2016; published 4 August 2016

Copyright (C) 2016 by author and Scientific Research Publishing Inc.

This work is licensed under the Creative Commons Attribution-NonCommercial International License (CC BY-NC).

http://creativecommons.org/licenses/by-nc/4.0/

(c) (i) (8) Open Access

\section{Abstract}

Background: Residual acetabular dysplasia is one of the main complications of developmental dysplasia of the hip (DDH). Without treatment, over time degenerative osteoarthritis of the joint will develop, inexorably leading to the need for joint replacement. Acetabular and/or femoral osteotomies do not avoid the appearance of osteoarthritis in a significant number of patients. The purpose of this study was to assess the possibility of provoking changes in the morphology of the acetabulum through selective epiphysiodesis of the extra-articular portion of the ilioischial arm of the triradiate cartilage, using a percutaneous cannulated screw with the guidance of an imaging intensifier in an experimental model in rabbits. Methods: In a pilot study, 3-week-old New Zealand rabbits $(n=20)$ were submitted to unilateral surgery of the hip while the contralateral hip of the same group was used as a control. Posterior epiphysiodesis to the triradiate cartilage of the acetabulum was performed by placement of a cannulated screw. The rabbits were followed-up until 18 weeks of life. Radiographic measurements of the hips were performed immediately postoperatively and at 12 weeks of life and before the rabbits were sacrificed at week 18. Three-dimensional computed tomography (3D-CT) scans were performed. Non-parametric tests for paired samples and the Wilcoxon test were used to compare the differences between group 1 and group 2 . A p < 0.05 was considered significant. Results: The non-intervened hips showed that, when the rabbit matured, the acetabulum lost concavity and depth. When comparing the median differences of the angles evaluated at 12 weeks between groups, a statistically significant difference was found in all radiographic measurements: an increase in Wiberg's angle but a decrease in acetabular index, acetabular angle of Sharp, acetabular depth index, and acetabular anteversion. Evaluating the operated hips at 12 and 18 weeks (three months after having removed the screw) using 3D-CT, we observed a rebound effect in the correction confirming that the effect obtained through selective 
epiphysiodesis did not cause the definitive closure of the cartilage. Conclusions: Selective growth arrest of the ilioischial arm of the triradiate cartilage (posterior epiphysiodesis) can alter growth and change the shape of the acetabulum in rabbits. A rebound effect was observed when the screw was removed, confirming that the technique did not provoke definitive closure of the physis. Level of evidence: Level-2, therapeutic study.

\title{
Keywords
}

\author{
Acetabular Dysplasia, Selective Epiphysiodesis, Rabbit Model
}

\section{Introduction}

Residual acetabular dysplasia is one of the main complications of developmental dysplasia of the hip (DDH). Without treatment, over time degenerative osteoarthritis of the joint will develop, inexorably leading to the need for joint replacement. Residual dysplasia is the major cause of total hip replacement in young adults [1]-[3].

Pediatric orthopedic surgeons have been trying to change the natural history of this defect through acetabular and/or femoral osteotomies [4]-[6]. Nevertheless, long-term follow-up studies have shown that such osteotomies do not avoid the appearance of osteoarthritis in a significant number of patients [7]. These difficulties have sparked the interest in developing a simpler and less aggressive method to obtain better long-term results. Iatrogenic or pathological lesions to the triradiate cartilage in skeletally immature patients have shown to lead to morphological changes in the development of the acetabulum [8] [9].

Our hypothesis is that residual dysplasia may be improved by provoking selective growth arrest of the ilioischial arm of the triradiate cartilage (posterior epiphysiodesis). The aim of this study was to assess the possibility to obtain morphological changes in the acetabulum through posterior epiphysiodesis to the triradiate cartilage by the percutaneous placement of a $2.7-\mathrm{mm}$ cannulated screw under imaging intensifier guidance in a pilot-model, experimental study in rabbits (Figure 1(a), Figure 1(b)).

To this aim, the following objectives were proposed: to evaluate the morphology of the acetabulum using radiographic measurements in skeletally immature and mature rabbits; to compare the development of the acetabulum using radiographic and three-dimensional computed tomography (3D-CT) measurements after modulation of the growth plate of the posterior triradiate cartilage in the same animals; to compare the morphology of the acetabulum by measuring the diameters and depth of the acetabulum by caliper after modulation of the growth plate of the posterior triradiate cartilage; and finally, to compare the development of the acetabulum using 3D-CT measurements after removing the screw used to obtain the modulation effect on the growth plate.

\section{Methods}

\subsection{Study Design}

A pilot study was conducted in 3-week-old New Zealand (number of animals: 20, 10 males and 10 females) rabbits submitted to unilateral surgery in one hip while the contralateral hip of the same group was used as a control. The operative side was chosen by random allocation. Posterior selective epiphysiodesis of the ilioischial arm of the extra articular portion of the triradiate cartilage was performed guided by an imaging intensifier using a 2.7-mm cannulated screw at three weeks of life (Figure 1(a), Figure 1(b)).

The rabbits were followed-up until they were 12 weeks of life. Anteroposterior radiographs of the pelvis were taken at 3 weeks and 12 weeks of life. At the latter moment a second intervention was performed to remove the device. Animals were sacrificed at the age of 18 weeks. Before that 3D-CT scans of the hips were also performed.

\subsection{Anesthetic Protocol}

Premedication with xylazine at $1 \mathrm{mg} / \mathrm{kg}$, a $30 \mathrm{mg} / \mathrm{kg}$ dose of ketamine, and midazolam at $0.1 \mathrm{mg} / \mathrm{kg}$ via intramuscular route were administered. Inhalant anesthesia was started with a mask using isoflurane (5\%) and subsequently, maintained at $0.5 \%$ with the addition of 1 gamma $/ \mathrm{kg}$ IV dose of fentanyl. Subcutaneous ketoprofen 6 


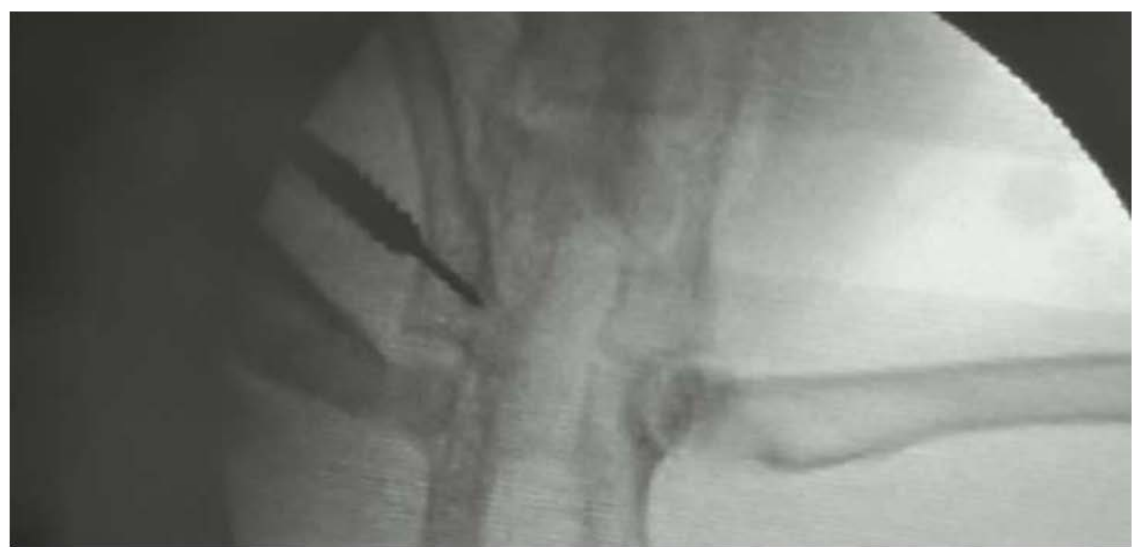

(a)

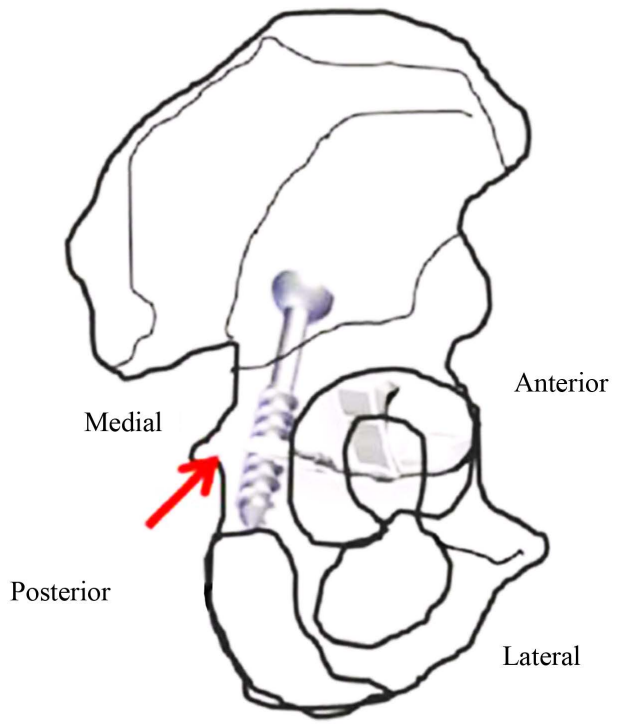

(b)

Figure 1. (a) A posterior oblique view of the coxis. The triradiate cartilage is marked and the red arrow identifies the area where the 2.7-mm cannulated screw was placed for the selective epiphysiodesis to the extraarticular portion of the ilioischialarm. (b) Percutaneous placement of a 2.7-mm cannulated screw under imaging intensifier.

$\mathrm{mg} / \mathrm{kg} /$ day and subcutaneous oxytetracycline $25 \mathrm{mg} / \mathrm{kg} /$ day were used for 4 days to control postsurgical pain and infections [10].

\subsection{Variables}

The following radiographic parameters were measured: Acetabular index (AI) [11] (Figure 2), lateral centeredge (CE) angle of Wiberg [12] (Figure 3), acetabular angle of Sharp (AS) [13] (Figure 4), and acetabular depth index (ADI) [14] (Figure 5).

Measurements were performed using IMPAX 6.5.3.1005 AGFA, 2013.

\subsection{Statistical Analysis}

a) List of data registration made in Excel,

b) Descriptive statistical analysis: mean, median, and standard deviation. Continuous variables are expressed as median and interquartile range (IQR, C25-C75) according to distribution,

c) Comparative statistical analysis: Wilcoxon matched pairs signed-ranks test, 2-tailed test. A P $<0.05$ was considered significant, 


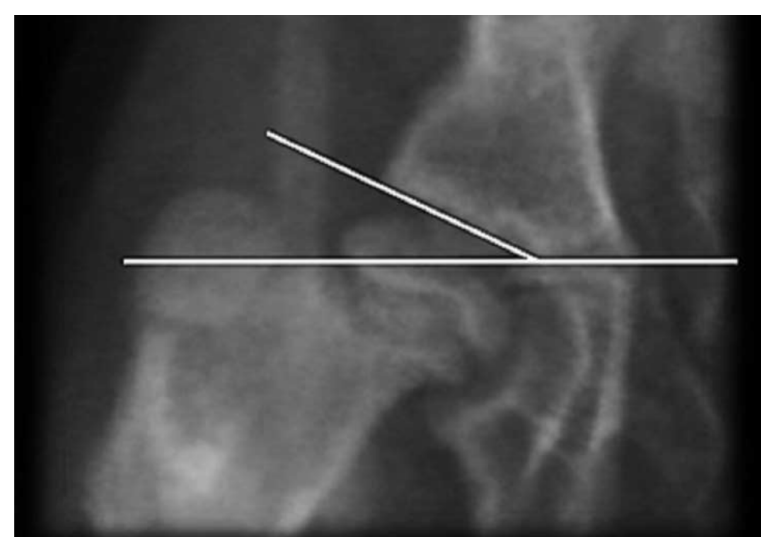

Figure 2. Acetabular index (AI): Formed by a horizontal line connecting both triradiate cartilages (Hilgenreiner line) and a second line extends along the acetabular roofs.

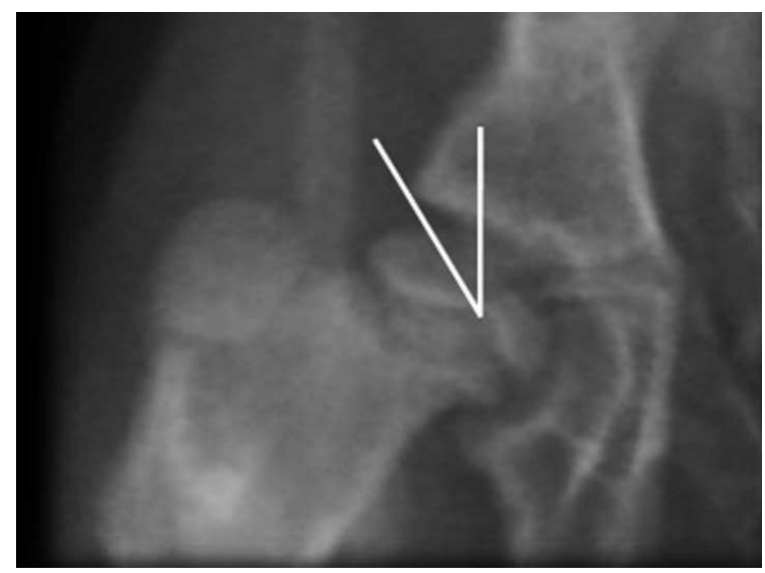

Figure 3. The lateral center-edge (CE) angle of Wiberg is measured by drawing a vertical line to the rotation center of the femoral head and from that center it is drawn a line to the superior and external edge of the acetabulum (n: $\left.25^{\circ}\right)$.

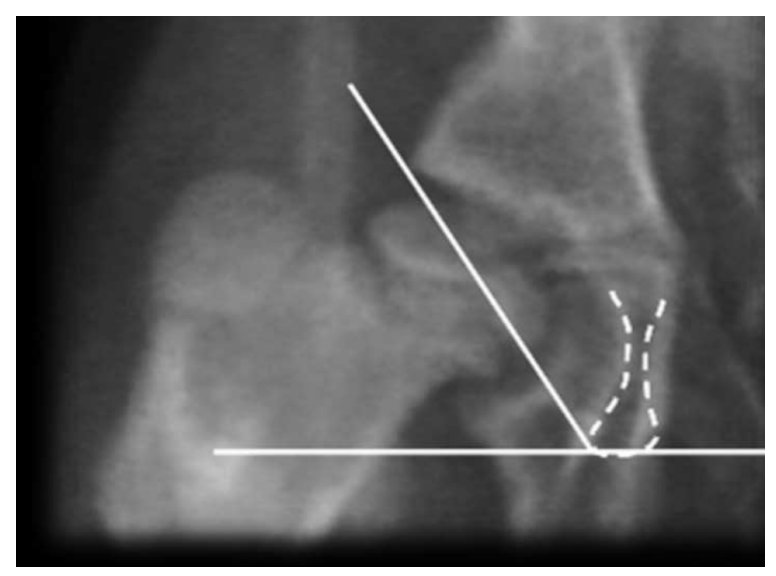

Figure 4. Acetabular angle of Sharp (AS) is measured with a line that unites the superior edge of the acetabulum with the inferior edge of the same forming an angle with the bi-isquiatic line (n: $42^{\circ}$ ). 


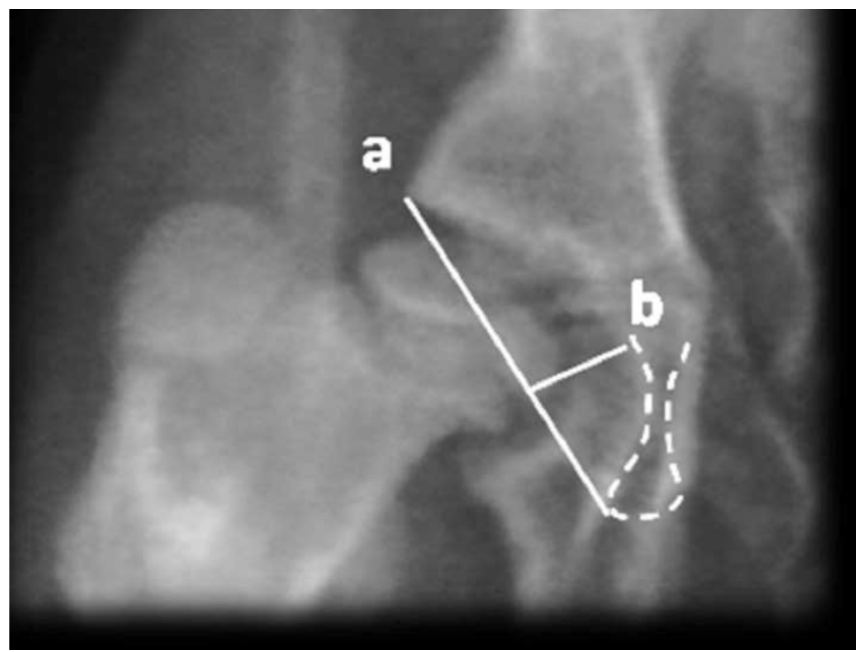

Figure 5. Acetabular depth index (ADI). Acetabulum Deepness is measured by drawing two vectors: the first one from the inferiorexternal edge until the superior-external of the acetabulum; the second is drawn a vector that is perpendicular to the anterior and that goes until the acetabular background marked by the line (ileopecten) of the iliopectineal eminence. It is calculated: $p=(b / a) \times 100 \%(n: 60 \%)$.

d) Sample size: determined by table for a mistake a $=0.05$, for power of $80 \%$ and for a size of expected effect of 0.80 ,

e) All the analyses and graphics were carried out with IBM SPSS, version 19.

To assess interobserver reliability and intraobserver reproducibility angular values founded a senior pediatric orthopedic surgeon and a senior musculoskeletal radiologist, measured the angles mentioned above in the radiographs taken at 3 and 12 weeks. In case of disagreement a second senior pediatric orthopedic surgeon, was consulted. The assessors were awarded the amount of time needed for evaluation, they were not allowed to discuss their results with their colleagues, and they were not informed about the X-ray re-evaluation. Two months later each participant was asked to reevaluate the same sets of X-rays in a different order.

Inter-observer agreement was calculated with the Cohen-Kappa value for inter-observer reliability using the Fleiss method and Kappa coefficient was defined according to the guidelines proposed by Landis and Koch with the following intervals: <0.00: poor accuracy; $0.00-0.20$ : slight accuracy; $0.21-0.40$ : reasonable accuracy; 0.41 - 0.60: moderate accuracy; 0.61 - 0.80: considerable accuracy and $0.81-1$ : accuracy almost perfect.

3D-CT scans were performed of the specimens after the rabbits were sacrificed.

The following parameters were compared between groups: ADI [15], CE angle of Wiberg, AS and Acetabular anteversion (AA) (Figure 6(a) and Figure 6(b)).

\subsection{Histological Study}

The morphology of the acetabulum was examined in the fresh specimen. We measured the diameters and depth of the acetabulum with a caliper. Depth of the acetabulum was measured in a uniform manner using the deepest point and the lateral margin of the acetabulum as landmarks. We also used a caliper to measure the percentage of area penetrated by the screw [16] [17].

In each animal, tissue for histological examination was obtained from both hips. The acetabulum was excised and fixated in formalin, decalcified in polyvinyl pyrrolidone and EDTA, and embedded in paraffin. The specimens were sectioned in the sagittal plane, obtaining tissue from the anterior and posterior limbs of the triradiatecartilage. The tissue was stained with Masson's trichrome and alcian blue.

\section{Ethical Approval}

All applicable international, national, and/or institutional guidelines for the care and use of animals were followed. 


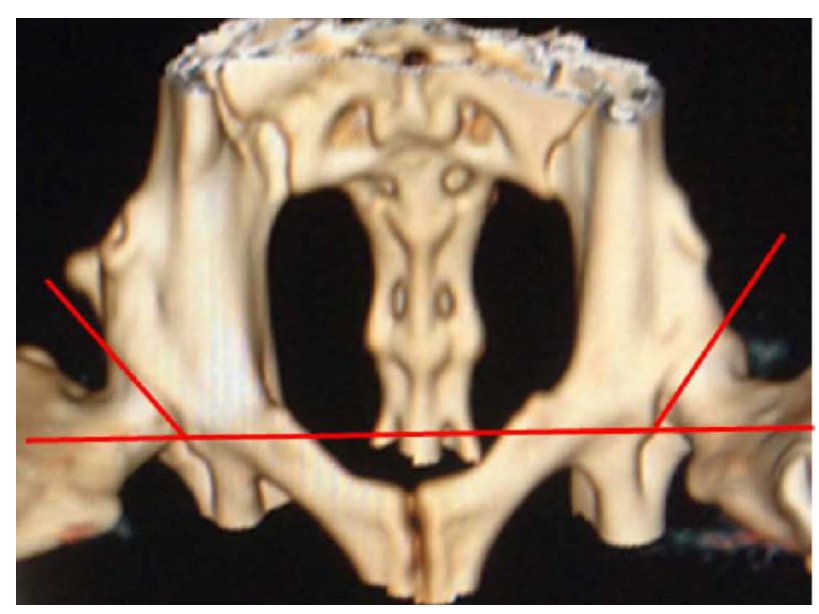

(a)

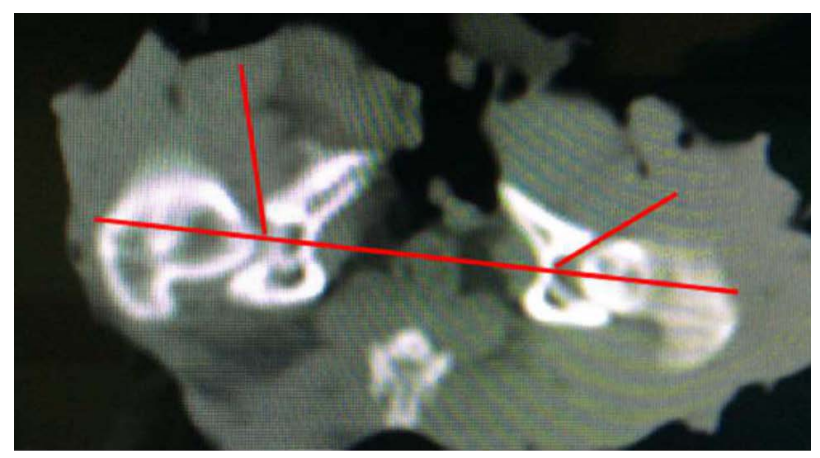

(b)

Figure 6. Acetabular antevertion (AA). It's measured in the true a-p, given by an angle taken from the inferior edge of the acetabulum drawing two vectors which directions are: the first one goes until the medial notch that corresponds to the ending of the anterior wall; the second vector goes until the superior-external edge of the acetabulum (n: 12 degrees). (a) Measured in 3D-CT, (b) Measured in CT scan.

This article does not contain any studies with human participants performed by any of the authors.

\subsection{Ethical Considerations and Statement of the Authors}

The authors have no conflict of interest to declare. No financial support was received for the study. Statistical analysis was performed by the authors and an independent specialist in health statistics.

\section{Results}

All the operated animals completed the study. The following complications were registered: a postoperative haematoma in the gluteus area that resolved without surgical treatment and a screw protrusion that did not interfere with the development of the study. There were no infections, extrusion or ruptures.

Radiographic results:

The Kappa inter-observer value between the two observers was: 0.86 for radiographic parameters.

In the second session, the Kappa values were 0.96 .

The Kappa values for each particular angle were 0.90 for the AI, 0.79 for the CE, 0.89 for the AS, and 0.78 for the ADI. In the second session, the Kappa values were 1 for the AI, 0.86 for the CE, and 0.91 for the AS and 0.87 for the ADI.

Normal changes of angle values in radiographic measurements at 3 and 12 weeks in the non-operated group are shown in Table 1. Statistically significant differences were found between results obtained at 3 weeks compared to those obtained at 12 weeks with increased angle values and a reduced angle of Wiberg (AI: 0.002; ADI: 
Table 1. Normal changes of angle values in radiographic measurements in hips without intervention $(n=20)$ Abbreviations: AI: acetabular index; CE: lateral center-edge angle; AS: acetabular angle of Sharp; ADI: acetabular depth index.

\begin{tabular}{ccccc}
\hline \multirow{2}{*}{ Angle } & \multicolumn{2}{c}{ Median } & \multicolumn{2}{c}{ Interquartile range (C25-C75) } \\
\cline { 2 - 5 } & 3 weeks & 12 weeks & 3 weeks & 12 weeks \\
\hline AI & $25.50^{\circ}$ & $30.98^{\circ}$ & $24^{\circ}-26.25^{\circ}$ & $30^{\circ}-32^{\circ}$ \\
CE & $28.00^{\circ}$ & $23.00^{\circ}$ & $26.75^{\circ}-28^{\circ}$ & $22^{\circ}-24^{\circ}$ \\
AS & $52.00^{\circ}$ & $57.50^{\circ}$ & $50^{\circ}-52.25^{\circ}$ & $56^{\circ}-58.5^{\circ}$ \\
ADI & $30.00 \%$ & $26.75 \%$ & $28.75 \%-31.5 \%$ & $24.75 \%-28.12 \%$ \\
\hline
\end{tabular}

0.001; CE: 0.001, AS: 0.001).

These changes show that, unlike in humans, in the skeletally maturing rabbit the acetabulum loses concavity and depth (Figure 7) [18] [19].

When comparing the median differences of the angles between groups evaluated at 12 weeks, a statistically significant difference was found in all radiographic measurements: an increase in Wiberg's angle but a decrease in Acetabular index, acetabular angle of Sharp, acetabular depth index, and acetabular anteversion.

The differences of the results between groups are shown in Table 2 (Figure 8).

Evaluating the operated hips at 12 and 18 weeks (three months after having removed the screw) by 3D-CT, we observed a rebound effect in the correction confirming that the effect obtained through selective epiphysiodesis does not cause definitive closure of the cartilage. However the growth decelerates compared to the control group within those same weeks. The differences are shown in Figure 9.

\section{Histological Results}

The acetabula of the operated group showed greater depths and concavity than those of the controls on morphometric analysis of the anatomical piece after the rabbits were sacrificed (Figure 10).

These findings coincided with the 3D-CT measurements. The differences are shown in Table 4. Penetrationof a screw into the joint in one specimen seen on 3D-CT was also confirmed by histology. Overall, the mean percentage of area penetrated by the screw was 95\% (range, 92\% - 97\%) of the total posterior ilioischial arm of the extraarticular portion of the triradiate cartilage, Histological study of the control group showed in microscopic evaluation the same pattern in all the samples: rounded cells occupied the zone with vascular penetration and endochondral ossification was observed (Figure 11) [20] [21].

Histological study of the intervention group showed a more advanced ossification process (Figure 12).

We did not use electron micrographs images

\section{Discussion}

In humans, as in most mammals, the acetabular complex is composed of three bone components: the ilium, the pubis, and the ischium connected by the triradiate cartilage as shown schematically in Figure 1 [22] [23]. The growth plates of the triradiate cartilage are important in the formation of the acetabulum, of which the congruence and spherical contour (concentricity) in humans develop quickly in the first eight years of life, to continue more slowly until complete physeal closure [24] [25].

Thus, growth of the acetabulum does not take place on a single plane, but on the three planes in the joint space. Each of the growth plates of which the triradiate cartilage is composed grows to achieve a normal acetabular diameter [26] [27].

A well-developed acetabulum has an adequate depth of its tear-drop image, a continuous Shenton's line that is concordant with the proximal femoral portion, and a good development of the acetabular index [28] [29].

Several osteotomies were designed to manage acetabular dysplasia, a surgery associated with a great degree of blood loss with the possible need of a second surgery when the growth plates close in adolescence, as this procedure per se may cause new deformities in the coxo-femoral joint produced by iatrogenic injury to the triradiate cartilage [30]-[32]. 


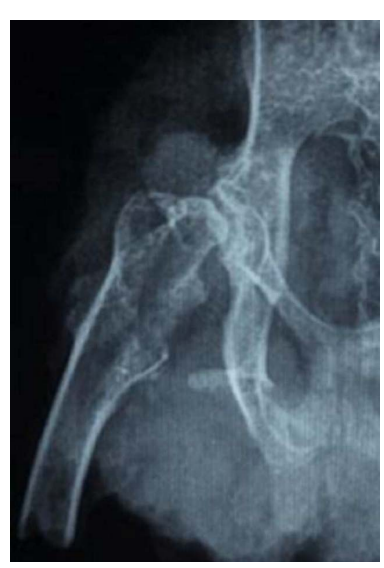

Figure 7. X-ray of a mature animal without treatment.

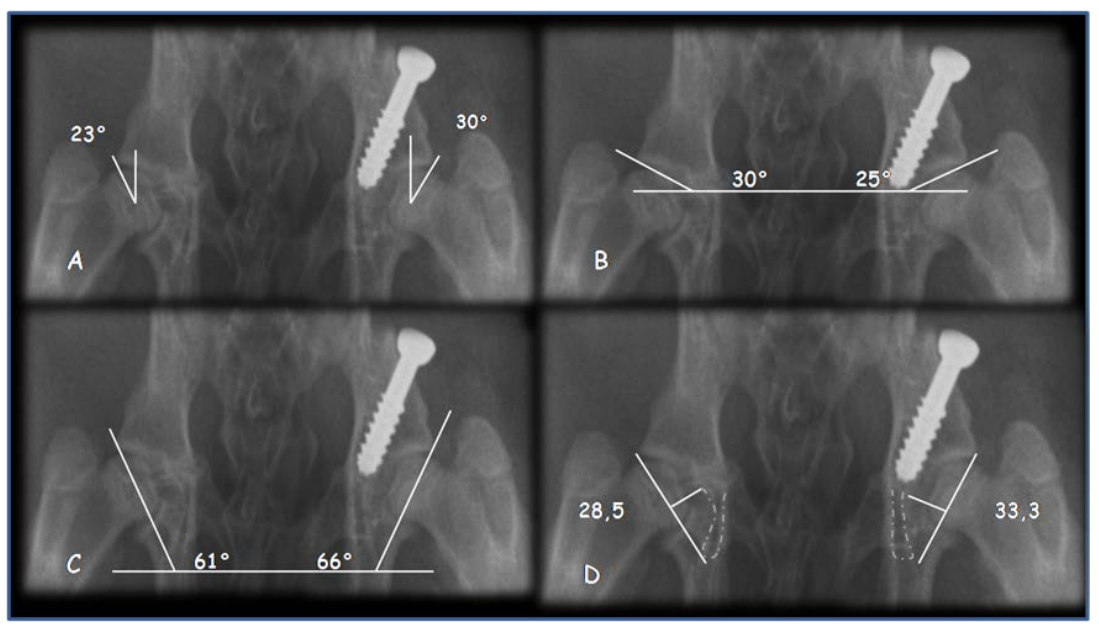

Figure 8. Radiographs of 12-week-old rabbits comparing right group-1 hips with left group-2 hips. (A) Lateral center-edge angle; (B) Acetabular index; (C) Angle of Sharp; (D) Acetabular depth index.

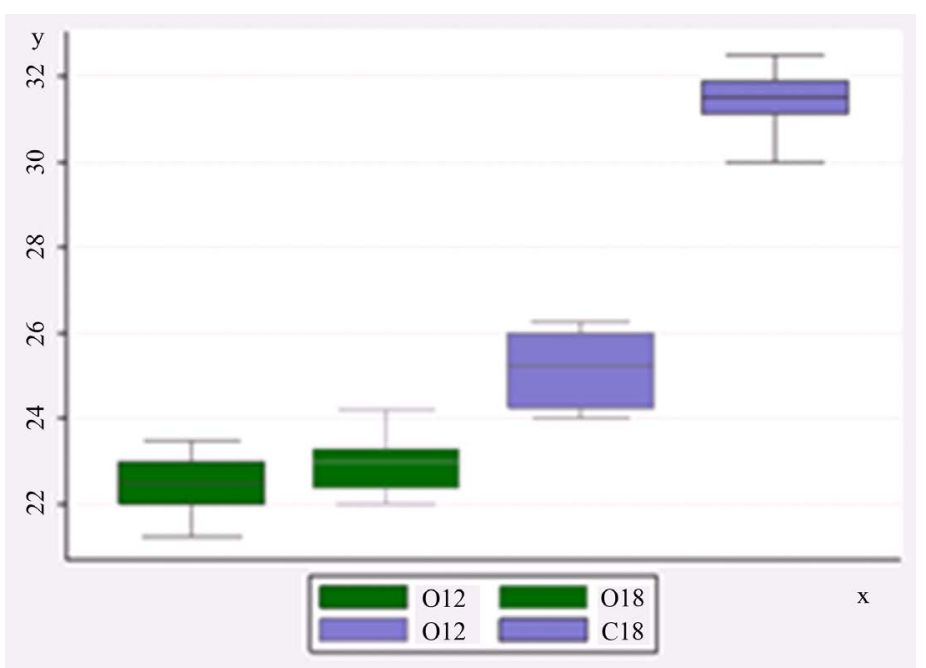

Figure 9. Comparisons of angle values between groups $(n=20)$ at weeks $12^{\text {th }}$ (when the screws were removed) and $18^{\text {th }}$ : it is clear that continued growth in the intervention group hips. $\mathrm{O}=$ intervened hips. $\mathrm{C}=$ hips not intervened. $\mathrm{x}$ : weeks; $\mathrm{y}$ : grades. 


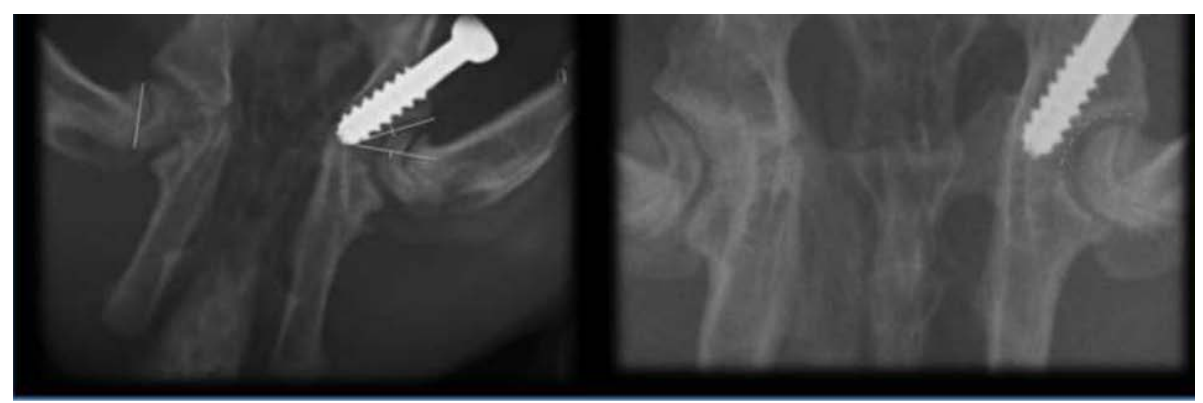

(a)

(b)

Figure 10. Radiographs images of the acetabulum of 12-week-old rabbits. (a) Left acetabulum in which normal development was not altered. (b) Right acetabulum in which epiphysiodesis was performed posterior to the triradiate cartilage. Greater depth is observed.

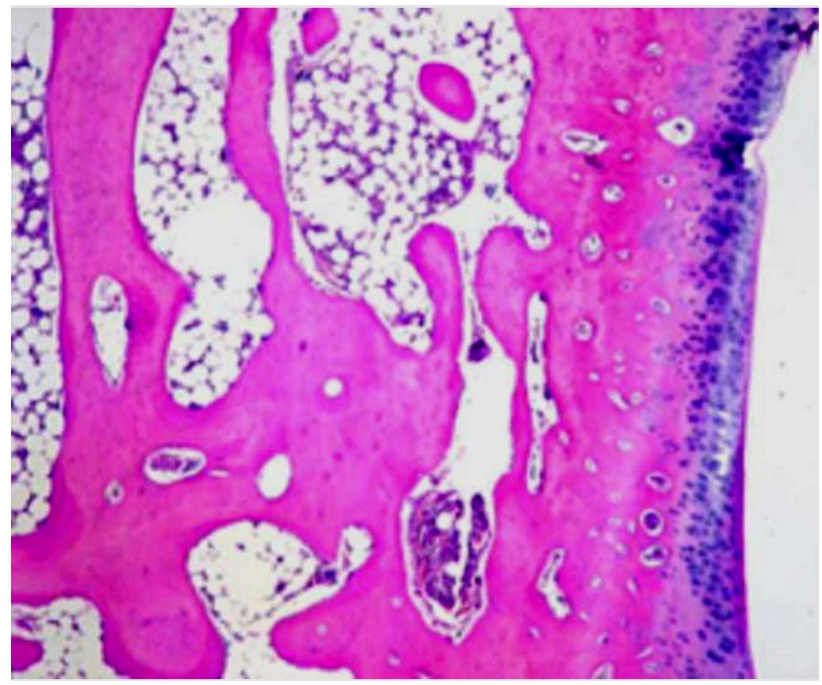

Figure 11. Histological study of group 1: rounded cells occupied the zone with vascularpenetration and enchondral ossification.

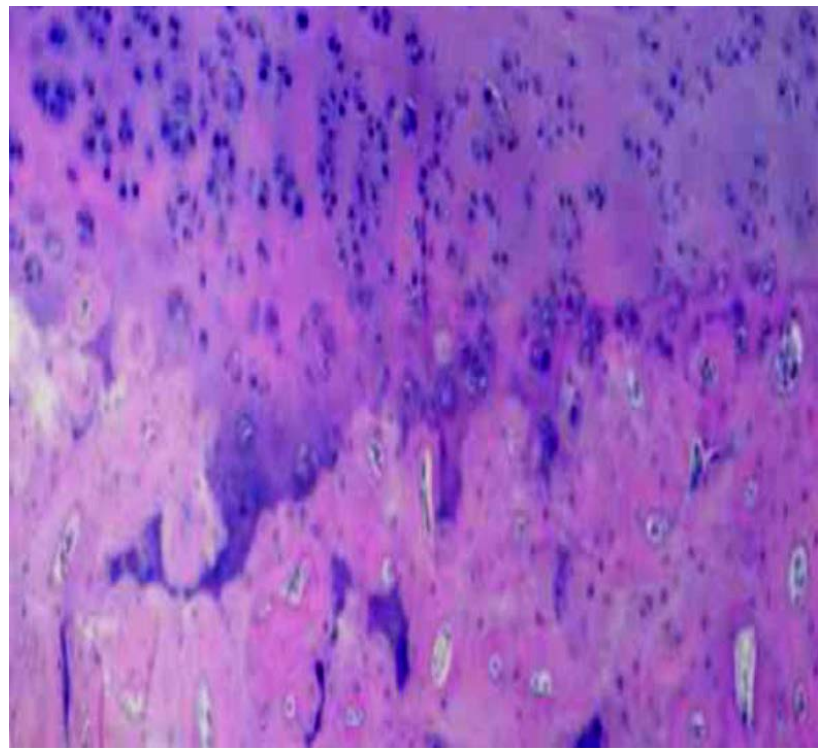

Figure 12. Histological study of the right hip showed a more advanced ossification process. 
Table 2. Comparisons of angle values of operated group vs. control group $(n=20)$ at 12 weeks.

\begin{tabular}{cccccc}
\hline & \multicolumn{2}{c}{ Operated hips } & \multicolumn{2}{c}{ Non operated hips } \\
\hline Angle & Median & $\begin{array}{c}\text { Interquartile range } \\
\text { (C25-C75) }\end{array}$ & Median & $\begin{array}{c}\text { Interquartile range } \\
\text { (C25-C75) }\end{array}$ \\
\hline AI & $22.43^{\circ}$ & $22-23$ & 30.98 & $30-32$ & 0.001 \\
CE & $28.0^{\circ}$ & $27-29.5$ & $23.0^{\circ}$ & $22^{\circ}-24^{\circ}$ & 5.002 \\
AS & $53.0^{\circ}$ & $52^{\circ}-54.5^{\circ}$ & $57.5^{\circ}$ & $-58.5^{\circ}$ & 0.002 \\
ADI & $31.5 \%$ & $30 \%-32.5 \%$ & $26.75 \%$ & $24.75 \%-28.12 \%$ & 0.002 \\
\hline
\end{tabular}

Cummings described experimentally how hinging in Pemberton osteotomy caused injury to the ilioischial limb; however, using this osteotomy better clinical results are obtained than with the Salter technique [33]. Our hypothesis draws on these findings: Residual dysplasia may be improved by provoking selective growth arrest of the ilioischial arm of the triradiate cartilage (posterior epiphysiodesis).

Here, we present preliminary data that support the hypothesis that selective growth arrest of the ilioischial arm of the triradiate cartilage (posterior epiphysiodesis) may alter growth and change the shape of the acetabulum (Table 2) showing how a selective percutaneous epiphysiodesis of the extra-articular part of the posterior limb of the triradiate cartilagesignificantly decreases the AI, the AS, and the ADI, while increasing the CE.

\section{Conclusions}

In conclusion, it seems that an imbalance exists between the ilioischial and the iliopubic limb of the triradiate cartilage and between the ilioischial limb and the superolateral part of the acetabular cartilage adjoining the ilium as Ponseti described [2]. Selective epiphysiodesis of the extra-articular portion of the ilioischial limb of the triradiate cartilage would correct this imbalance and improve acetabular dysplasia.

Moraleda, Albinana, and Forriol [34] have reported in an experimental study that it is feasible to provoke changes similar to those that occur in DDH by immobilizing the knee in extension in 3-week-old rabbits followed by selective epiphysiodesis of the triradiate cartilage (with open curettage) in the dysplastic hip, normalizing radiographic measurements and depth of the acetabulum [35].

The results of this study show that acetabular maturity in rabbits entails morphological changes that are different from those in humans. In the human, the ilio-ischial limb is twice the size of the ilio-pubic-limb; while in the rabbit it is three times the size. The predominance may be responsible for the effect of the premature fusion on acetabular development. As the rabbit skeletally matures, the acetabulum loses concavity and depth (Table 1). This may be explained by the fact that quadrupeds distribute the weight of their body differently than humans [8].

Selective epiphysiodesis is an accepted procedure for the correction of angle deformities in the lower limbs; however, percutaneous epiphysiodesis of the triradiate cartilage has not been performed in clinical studies. Here the effect produced by this selective epiphysiodesis is shown in a three-dimensional model. Acetabular growth modulation may be beneficial, especially in children with residual hip dysplasia secondary to DDH.

Additionally, in the literature there have been reports of techniques for the release of physeal bars in patients who suffered damage to the acetabular growth plate due to pelvic fractures [33] with uncertain results. Because of that good results may be obtained performing this intervention with the percutaneous placement of a 2.7-mm cannulated screw. Nevertheless, a rebound effect in the correction was observed when the screw was removed confirming that the effect obtained does not cause the definitive closure of the cartilage (Table 3). This study does not show how growth continues after the screw is removed from the triradiate cartilage; however, using similar techniques in the management of angle deformities in the lower limbs, growth of the limb resumes after screw removal [36]. Indeed, no physeal bars are found in histological sections of the areas operated.

Selective epiphysiodesis of the ilioischial limb of the triradiate cartilage also improves acetabular depth with good femoral head congruency. We demonstrated a statistically significant difference when comparing morphometric analysis and 3D-CT images (Table 3, Table 4).

Given its potential benefits and low morbidity (one postoperative haematoma and one screw protrusion) associated with this minimal approach, limited blood loss, and fast mobilization, epiphysiodesis of the triradiate cartilage may be a useful complementary procedure for the treatment or prevention of residual dysplasia in children 
Table 3. Comparisons of angle values of the operated group $(n=20)$ at weeks 12 and 18 when the screw was removed.

\begin{tabular}{cccccc}
\hline & \multicolumn{2}{c}{ Operated hips at 12 weeks } & \multicolumn{2}{c}{ Operated hips at 18 weeks } & \multirow{2}{*}{ p } \\
\cline { 1 - 4 } Angle & Median & $\begin{array}{c}\text { Interquartile range } \\
\text { (C25-C75) }\end{array}$ & Median & $\begin{array}{c}\text { Interquartile range } \\
\text { (C25-C75) }\end{array}$ & \\
\hline AI & $22.43^{\circ}$ & $22-23$ & $24.50^{\circ}$ & $31.125-31.9$ & 0.001 \\
CE & $28.0^{\circ}$ & $27-29.5$ & $25^{\circ}$ & $23^{\circ}-26.5^{\circ}$ & 0.002 \\
AS & $56.0^{\circ}$ & $55^{\circ}-57.5^{\circ}$ & $59^{\circ}$ & $58^{\circ}-61.5^{\circ}$ & 0.002 \\
ADI & $31.5 \%$ & $30 \%-32.5 \%$ & $28.8 \%$ & $27 \%-29.5 \%$ & 0.002 \\
Acetabular anteversion (AA) & $12.5^{\circ}$ & $11.5^{\circ}-13^{\circ}$ & $11^{\circ}$ & $10^{\circ}-11.5^{\circ}$ & 0.002 \\
\hline
\end{tabular}

Table 4. Comparison of Morphometric analysis.

\begin{tabular}{|c|c|c|c|c|c|}
\hline \multirow[b]{2}{*}{$\begin{array}{l}\text { Morphometric analysis of } \\
\text { Acetabular diameters: }\end{array}$} & \multicolumn{2}{|c|}{ Operated hips } & \multicolumn{2}{|c|}{ Non operated hips } & \multirow[b]{2}{*}{$\mathrm{p}$} \\
\hline & Median & $\begin{array}{l}\text { Interquartile range } \\
\text { (C25-C75) }\end{array}$ & Median & $\begin{array}{l}\text { Interquartile range } \\
\text { (C25-C75) }\end{array}$ & \\
\hline Infero-superior (mm) & 89 & $87-89.5$ & 83.0 & $82-84$ & 0.002 \\
\hline Antero-posterior (mm) & 87.0 & $85-87.5$ & 83.5 & $82-84.5$ & 0.005 \\
\hline Acetabular deepness (mm) & 6.5 & $5.0-5.8$ & 3.75 & $3.4-3.92$ & 0.002 \\
\hline
\end{tabular}

with DDH [37].

We emphasize that the results of this study are preliminary and therefore further research is necessary to be able to draw any definitive conclusions.

\section{References}

[1] Morcuende, J.A., Meyer, M.D., Dolan, L.A. and Weinstein, S.L. (1997) Long Term Outcome after Open Reduction through an Anteromedial Approach for Congenital Dislocation of the Hip. Journal of Bone and Joint Surgery-American, 79, 810-817.

[2] Ponseti, I.V. (1978) Growth and Development of the Acetabulum in the Normal Child. Anatomical, Histological, and Roentgenographic Studies. Journal of Bone and Joint Surgery-American, 60, 575-585.

[3] Weinstein, S.L., Mubarak, S.J. and Wenger, D.R. (2004) Developmental Hip Dysplasia and Dislocation: Part I. Instructional Course Lectures, 53, 523-530.

[4] Weinstein, S.L., Mubarak, S.J. and Wenger, D.R. (2004) Developmental Hip Dysplasia and Dislocation: Part II. Instructional Course Lectures, 53, 531-542.

[5] Salter, R.B. (1961) Innominate Osteotomy in the Treatment of Congenital Hip Dislocation and Subluxation of the Hip. Journal of Bone and Joint Surgery-British, 43, 518-539.

[6] Albinana, J., Dolan, L.A., Spratt, K.F., Morcuende, J., Meyer, M.D. and Weinstein, S.L. (2004) Acetabular Dysplasia after Treatment for Developmental Dysplasia of the Hip. Implications for Secondary Procedures. Journal of Bone and Joint Surgery-British, 86, 876-886. http://dx.doi.org/10.1302/0301-620X.86B6.14441

[7] Engesaeter, L.B., Furnes, O. and Havelin, L.I. (2008) Developmental Dysplasia of the Hip-Good Results of Later Total hip Arthroplasty: 7135 Primary Total Hips Arthroplasties after Developmental Dysplasia of the Hip Compared with 59,774 Total Hips Arthroplasties in Idiopathic Coxarthrosis Followed for 0 to 15 Years in the Norwegian Arthroplasty Register. The Journal of Arthroplasty, 23, 235-240.

[8] Bucholz, R.W., Ezaki, M. and Ogden, J.A. (1982) Injury to the Acetabular Triradiate Physeal Cartilage. Journal of Bone and Joint Surgery-American, 64, 600-609.

[9] Scuderi, G. and Bronson, M.J. (1978) Triradiate Cartilage Injury. Report of Two Cases and Review of the Literature. Clinical Orthopaedics and Related Research, No. 217, 179-189.

[10] Los roedores de laboratorio como modelos de enfermedades humanas. Manual de genética de roedores de laboratorio. Ed-Panamericana., 263-297.

[11] Hilgenreiner, H. (1986) Hingenreiner on Congenital Hip Dislocation. JPO, 6, 207, Fig. 1. 
[12] Sharp, I.K. (1961) Acetabular Dysplasia. The Acetabular Angle. Journal of Bone and Joint Surgery, 43B, 268-272.

[13] Wiberg, G. (1939) Studies on Dysplastic Acetabula and Congenital Subluxation of the Hip Joint with Special References to the Complication of OSteoarthritis. Acta Chirurgica Scandinavica, 83, 58.

[14] Cooperman, D.R., Wallensten, R. and Stulberg, S.D. (1983) Acetabular Dysplasia in the Adult. Clinical Orthopaedics and Related Research, 175, 79-85.

[15] Daysal, G.A., Goker, B., Gonen, E., Demirag, M.D., Haznedaroglu, S., Ozturk, M.A. and Block, J.A. (2007) The Relationship between Hip Joint Space Width, Center Edge Angle and Acetabular Depth. Osteoarthritis and Cartilage, 15, 1446-1451. http://dx.doi.org/10.1016/j.joca.2007.05.016

[16] Seinsheimer, F. and Sledge, C. (1981) Parameters of Longitudinal Growth Rate in Rabbit Epiphyseal Growth Plates. The Journal of Bone \& Joint Surgery, 63, 627-630.

[17] Shaw, N. and Lacey, E. (1975) The Influence of Corticosteroids on the Normal and Papain Treated Epiphyseal Growth Plate in the Rabbit. The Journal of Bone \& Joint Surgery, 57, 228-233.

[18] Páez, J., Hennessey Montilla, R., Armando Amador, J. and Martínez, C. (2006) Efecto de la oxitetraciclina sobre el cartílago articular. Revista Colombiana de Ortopedia y Traumatología, 20, 48-54.

[19] Chen, I.H., Kuo, K.N. and Lubicky, J.P. (1994) Prognosticating Factors Inacetabular Development Following Reduction of Developmental Dysplasia of the Hip. Journal of Pediatric Orthopaedics, 14, 3-8. http://dx.doi.org/10.1097/01241398-199401000-00002

[20] Lindstrom, J.R., Ponseti, I.V. and Wenger, D.R. (1979) Acetabular Developmental after Reduction in Congenital Dislocation of the Hip. The Journal of Bone \& Joint Surgery, 61, 112-118.

[21] Tönnis, D. (1987) Displasia Congénita y la luxación de cadera en niños y adultos. Springer, Berlín.

[22] Weintroub, S., Green, I., Terdiman, R. and Weissman, S.L. (1979) Growthand Development of Congenitally Dislocated Hips Reduced Inearly Infancy. The Journal of Bone \& Joint Surgery, 61, 125-130.

[23] Gepstein, R., Weiss, R.E. and Hallel, T. (1984) Acetabular Dysplasia and Hip Dislocation after Selective Premature Fusion of the Triradiate Cartilage: An Experimental Study in Rabbits. The Journal of Bone \& Joint Surgery, 66, 334336.

[24] Isiklar, Z.U., Kandemir, U., Ucar, D.H. and Tumer, Y. (2006) Is Concomitantbone Surgery Necessary at the Time of Open Reduction Indevelopmental Dislocation of the Hip in Children 12-18. Journal of Pediatric Orthopedics. Part B, 15, 23-27. http://dx.doi.org/10.1097/01202412-200601000-00005

[25] Hallel, T. and Salvati, E.A. (1977) Premature Closure of the Triradiate Cartilage: A Case Report and Animal Experiment. Clinical Orthopaedics and Related Research, 124, 278-281. http://dx.doi.org/10.1097/00003086-197705000-00038

[26] Shapiro, F., Koide, S. and Glimcher, M.J. (1993) Cell Origin and Differentiation in the Repair of Full-Thickness Defects of Articular Cartilage. The Journal of Bone \& Joint Surgery, 75, 532-553

[27] Kim, H.W., Morcuende, J.A., Dolan, L.A. and Weinstein, S.L. (2000) Acetabular Development in Developmental Dysplasia of Thehip Complicated by Lateral Growth Disturbance of the Capital Femoral Epiphysis. The Journal of Bone \& Joint Surgery, 82, 1692-1700.

[28] Bicimoglu, A., Agus, H., Omeroglu, H. and Tumer, Y. (2003) Six Years of Experience with a New Surgical Algorithm in Developmental Dysplasia of the Hip in Children under 18 months of Age. Journal of Pediatric Orthopaedics, 23, 693-698.

[29] Luhmann, S.J., Bassett, G.S., Gordon, J.E., Schootman, M. and Schoenecker, P.L. (2003) Reduction of a Dislocation of the Hip Due to Developmental Dysplasia, Implications for the Need for Future Surgery. The Journal of Bone \& Joint Surgery, 85, 239- 243.

[30] Delgado-Baeza, E., Sanz-Laguna, A. and Miralles-Flores, C. (1991) Experimental Trauma of the Triradiate Epiphysis of the Acetabulum and Hip Dysplasia. International Orthopaedics, 15, 335-339. http://dx.doi.org/10.1007/BF00186873

[31] Delgado Baeza, E., Gil Garay, E., Serrada Hierro, A., Davidson, W.M. and Miralles Flores, C. (1988) Experimental Acetabular Dysplasia Associated with a Lesion of Iliopubic Limb of the Triradiate Cartilage. Clinical Orthopaedics and Related Research, 234, 75-81. http://dx.doi.org/10.1097/00003086-198809000-00016

[32] Kuba, A. (1986) Growth Disturbance of the Acetabulum by Damage to the Triradiate Cartilage of Rabbits. Nihon Seikeigeka Gakkai Zasshi, 60, 215-225

[33] Peterson, H.A. and Robertson, R.C. (1997) Premature Partial Closure of the Triradiate Cartilage Treated with Excision of a Physical Osseous Bar. Case Report with a Fourteen-Year Follow-Up. The Journal of Bone \& Joint Surgery, 79, 767-770

[34] Luis Moraleda, M.D., Javier Albiñana, M.D. and Francisco Forriol, M.D. (2013) Selective Epiphysiodesis of the Trira- 
diate Cartilage for Treatment of Residual Experimental Acetabular Dysplasia. Journal of Pediatric Orthopaedics, 33, 821-828. http://dx.doi.org/10.1097/BPO.0b013e31829b2f3f

[35] Hernández, S. (2006) El modelo animal en las investigaciones biomédicas. Biomedicina, 2, 252-256.

[36] Agus, H., Kalenderer, Ö., Bicimoglu, A. and Tümer, A. (2006) Can Percutaneous Epiphysodesis of Medial Proximal Femur Physis Be Effective for Treatment. 25th European Paediatric Orthopaedeic Society Abstract Book, Dresden, 5-8 April 2006, 5-75.

[37] Ucar, D.H., Isiklar, Z.U., Stanitski, C.L., Kandemir, U. and Tumer, Y. (2004) Open Reduction through a Medial Approach in Developmental Dislocation of the Hip: A Follow-Up Study to Skeletal Maturity. Journal of Pediatric Orthopaedics, 24, 493-500. http://dx.doi.org/10.1097/01241398-200409000-00008

\section{Submit or recommend next manuscript to SCIRP and we will provide best service for you:}

Accepting pre-submission inquiries through Email, Facebook, LinkedIn, Twitter, etc.

A wide selection of journals (inclusive of 9 subjects, more than 200 journals)

Providing 24-hour high-quality service

User-friendly online submission system

Fair and swift peer-review system

Efficient typesetting and proofreading procedure

Display of the result of downloads and visits, as well as the number of cited articles

Maximum dissemination of your research work

Submit your manuscript at: http://papersubmission.scirp.org/ 